\title{
A propósito del Estudio práctico sobre la fiebre tifoidea de Chile de Joaquín Zelaya, 1881
}

ENRIQUE LAVAL R.

\author{
In connection with the "Practical study about Typhoid Fever of Chile" \\ by Joaquín Zelaya, 1881
}

Don Joaquín Zelaya se tituló de médico el 10 de diciembre de 1856. Su tesis de licenciado versó sobre "Las fiebres remitentes en la ciudad de Curicó". Siendo todavía estudiante de Medicina del último curso, ocupó el cargo de Médico de aquella ciudad. Ahí contrajo matrimonio y fue dueño de tierras en Romeral, donde introdujo cepas de uvas francesas, plantando una viña en su propiedad ${ }^{2}$.

Poco después de obtenido su título, se instaló en Valparaíso, iniciando con este cambio una larga peregrinación por muchas ciudades del país². En 1866 se recibió también en el Uruguay. Durante algún tiempo recorrió gran parte de la República Argentina, Uruguay y sur de Brasil, ejerciendo su profesión y realizando exploraciones mineras.

Desde el comienzo de la Guerra del Pacífico fue jefe del Hospital de Sangre de La Serena, donde ideó puso en práctica la irrigación y continua, gota a gota de las heridas de guerra infectadas, agregando generalmente al agua, licor de Labarraque (solución de hiposulfito de sodio), ácido carbólico y otros antisépticos. Los resultados fueron extraordinariamente buenos en un centenar de casos. Según Sierra y Reccius, este era el mismo método llamado de DakinCarrel, tan empleado en la Primera Guerra Mundial (1914-1918) y que adquiriera prestigio universal. El doctor Zelaya publicó su experiencia en la Revista Médica de Chile de 1880, intitulada "Tratamiento de la gangrena por el sistema de irrigación continua en el Hospital de Sangre de La Serena". Este procedimiento antiséptico es tal vez el aporte más importante al progreso de la cirugía de la época, por su originalidad y eficacia. Resulta trágico pensar que la ignorancia, ceguera y los prejuicios de aquellos tiempos, no hayan puesto al alcance de los heridos de todo el mundo un procedimiento tan valioso, con anticipación de casi 40 años.

El doctor Zelaya escribió un Manual Práctico de las Enfermedades Venéreas y Sifílicas. Puesto al alcance de todo el mundo y cuando ejerció en Mendoza en 1887, publicó "El Cólera Morbo: su tratamiento por inyecciones hipodérmicas". Otros escritos suyos fueron "Apuntes sobre la tisis pulmonar" y "Causas de la mortandad de niños en Chile".

A continuación nos referiremos a su "Estudio Práctico sobre la Fiebre Tifoidea de Chile", impreso en La Serena en Julio de 1881 ciudad en la que falleció en 1900 .
Dirigiéndose al cuerpo médico de Chile, Zelaya considera que la "fiebre tifoidea es la fiebre más grave que existe en Chile" y agrega que "este estudio es el resultado de mi práctica; mi manera de ver y apreciar esta enfermedad, después de haberla observado en casi todos los pueblos de Chile".

En 102 páginas, divididas en 12 capítulos, Joaquín Zelaya comienza por definir a la "fiebre tifoidea del clima de Chile", diciendo que es una fiebre séptica y continua que se localiza en las meninges y el aparato intestinal, provocando en éste la inflamación ulcerosa de sus membranas y ganglios mesentéricos y que perturba profundamente los centros nerviosos". Agrega que existe en todo Chile, "pero es más frecuente en la parte central, manifestando "que en una época, fue epidémica en Santiago y muy frecuente en Valparaíso. La Serena, Concepción, Curicó y Talca; en los puertos cuyas riveras son sucias por los desperdicios que en ellas se arrojan y por lo que el mar deposita, puede decirse que la tifoidea es endémica. En, verano sobre todo".

En cuanto a la etiología declara que "por causas ocultas en el mismo organismo y desconocidas en el exterior, se provoca espontáneamente en el sistema el elemento séptico, análogo al del tifus, angina, fiebres pútridas, etc ${ }^{6}$. Hay que recordar que un año antes (1880), de la publicación de este libro, se inició una nueva época con el descubrimiento del bacilo tífico, simultáneamente por Eberth, Roberto Koch y Wilh.

La descripción clínica de la enfermedad, que hace el doctor Zelaya, casi no se aparta, de lo que leemos en los antiguos tratados de patología infecciosa. Su estilo y la minuciosidad con que detalla la sintomatología y signología son dignos de destacarse.

En el siglo XIX y tal vez algo antes, contemplaba clásicamente el tratamiento de la fiebre tifoidea, tres premisas o indicaciones:

- Disminuir la "formación de toxinas", evitando su "retención y facilitando la eliminación".

- Combatir la pirexia

- Sostener o en lo posible aumentar "las fuerzas y defensas del enfermo".

Para cada una de ellas existía una medicación particular: antiséptica, antitérmica y tónica.

Entre otros, se utilizaba como antisépticos, el 
calomelano, el yodoformo, el naftol y el salol. Estas sustancias fueron abandonándose en forma paulatina, al comprobarse su nula eficacia. Junto con estos medicamentos se empleaba, a fin de "eliminar las toxinas", enemas y lavados intestinales con diversas fórmulas.

La terapia antipirética era medicamentosa y refrigerante. Como antitérmico de primera elección, se utilizaba desde 1848 la quinina, por lo general, como sulfato o clorhidrato-sulfato, con distintos esquemas, de acuerdo a la magnitud de la pirexia. El doctor Zelaya se muestra ardiente partidario de este fármaco, llegando a señalar con entusiasmo, que "es el medicamento específico en el tratamiento de la fiebre tifoidea, cuando se lo emplea correctamente". Menos usados fueron los compuestos salicilados y la antipirina.

El "baño frío sistemático" representaba, "el procedimiento más eficaz de la antipirexia hidriática".

El alcohol era el elemento fundamental de la terapia tónica. Jaccoud aconsejaba dar "30 a 80 gramos de ron o coñac, en una poción cordial, o bien, 250 gramos de vino de Burdeos". Según se estimaba estas prescripciones eran de "gran utilidad en los enfermos alcohólicos", pero estaban contraindicadas en los jóvenes y en aquellos con delirio violento.

El doctor Zelaya no se apartaba mucho de estas normas terapéuticas, pero "cuando en el cerebro el dolor es muy intenso, la inyección de las conjuntivas muy pronunciada; cuando sobrevienen somnolencia o coma, convulsiones, pesadez de la cabeza, cierta contracción del iris y con esto pulso frecuente, temperatura muy elevada, epistaxis y algunas simpatías gástricas expresadas por náuseas o vómitos sin vacilar debe repetirse las sanguijuelas en las apófisis mastoideas y las ventosas escarificadas en la parte posterior del cuello y de la nuca". Así de simple.

Termina señalando que "esta enfermedad como cualquiera otra tiene sus particularidades y siendo en Chile la más seria y grave, justo es que le prestemos atención preferente para conocerla bien y si es posible establecer, sobre bases muy sólidas su método curativo".

Deberían pasar casi 70 años para que este anhelo del doctor Zelaya se cumpliera a cabalidad, con el descubrimiento del cloranfenicol y su gran éxito en el tratamiento de la fiebre tifoidea, enfermedad que en Chile, pareciera haber comenzado a "transitar por los umbrales de la historia".

\section{Bibliografía}

1.- Laval M E. Noticias sobre los médicos en Chile. XIX (letra Z). Inédito.

2.- Correa C H. Historia de la Medicina de la Provincia de Curicó. (1536-1963) An Chil Hist Med 1964; 6 Vol 1: 202.

3.- Cornejo G G. Introducción del método Dr Lister en Chile. An Chil Hist Med. 1967; 6 (9-10): 55.

4.- Sierra M L. Lord Lister. La cirugía antiséptica. Rev Méd Chile 1903; 31: 5.

5.- Reccius A. Historia y desarrollo de la cirugía abdominal. Chile. (1)88 Ed... Zig-Zag. 1948. Santiago de Chile.

6.- Zelaya L. Estudio Práctico sobre la fiebre tifoidea de Chile. Imprenta de la Reforma. La Serena. Chile. 1881.

7.- Von Bergmann O, Staehelin R. Tratado de Medicina Interna. Enfermedades infecciosas. Tomo $12 \sim$ parte. Ed Labor Barcelona. España. 1- 942.

8.- Debove G N, Achard C H. Manuel de Médicine. Maladies Infectieuses. Tomo VIII Rueff et cie. Ed. Paris, Francia. 1897.

9.- García Del Real E. Fiebre tifoidea. lid. N'lorata. Barcelona, España. 1942. 